\title{
Genetic diversity of Halla horses using microsatellite markers
}

\author{
Joo-Hee Seo ${ }^{1,2}$, Kyung-Do Park ${ }^{3}$, Hak-Kyo Lee ${ }^{3}$ and Hong-Sik Kong ${ }^{1,2^{*}}$ (D)
}

\begin{abstract}
Background: Currently about 26,000 horses are breeding in Korea and 57.2\% (14,776 horses) of them are breeding in Jeju island. According to the statistics published in 2010, the horses breeding in Jeju island are subdivided into Jeju horse (6.1\%), Thoroughbred (18.8\%) and Halla horse (75.1\%). Halla horses are defined as a crossbreed between Jeju and Thoroughbred horses and are used for horse racing, horse riding and horse meat production. However, little research has been conducted on Halla horses because of the perception of crossbreed and people's weighted interest toward Jeju horses.

Method: Using 17 Microsatellite (MS) Markers recommended by International Society for Animal Genetics (ISAG), genomic DNAs were extracted from the hair roots of 3,880 Halla horses breeding in Korea and genetic diversity was identified by genotyping after PCR was performed.

Results and conclusion: In average, 10.41 alleles (from 6 alleles in HTG7 to 17 alleles in ASB17) were identified after the analysis using $17 \mathrm{MS}$ Markers. The mean value of $\mathrm{H}_{\mathrm{obs}}$ was 0.749 with a range from 0.612 (HMS1) to 0. 857(ASB2). Also, it was found that $\mathrm{H}_{\text {exp }}$ and PIC values were lowest in HMS1 (0.607 and 0.548, respectively), and highest in LEX3(0.859 and 0.843, respectively), and the mean value of $\mathrm{H}_{\text {exp }}$ was 0.760 and that of PIC was 0.728 . 17 MS markers used in this studies were considered as appropriate markers for the polymorphism analysis of Halla horses. The frequency for the appearance of identical individuals was $5.90 \times 10^{-20}$ when assumed as random mating population and when assumed as half-sib and full-sib population, frequencies were $4.08 \times 10^{-15}$ and $3.56 \times 10^{-8}$, respectively. Based on these results, the $17 \mathrm{MS}$ markers can be used adequately for the Individual Identification and Parentage Verification of Halla horses. Remarkably, allele M and Q of ASB23 marker, G of HMS2 marker, H and L of HTG6 marker, L of HTG7 marker, E of LEX3 marker were the specific alleles unique to Halla horses.
\end{abstract}

Keywords: Microsatellite marker, Halla Horse, Polymorphism, Allele frequency

\section{Background}

Horses (: Equus caballus) were first domesticated 4000 years ago and they are one of the most important animals for human and currently, about 200 horse breeds are breeding in the world. In the past years they were used as meat animals, workhorses or transportation means, but nowadays they are used for the various purposes such as improvement of life quality and development of leisure culture.

\footnotetext{
* Correspondence: kebinkhs@hknu.ac.kr

'Genomic Informatics Center, Hankyong National University, Anseong 17579, Korea

${ }^{2}$ Department of Genomic Informatics, Graduate School of Future Convergence Technology, Hankyong National University, Anseong 456-749, Korea

Full list of author information is available at the end of the article
}

Currently about 26,000 horses are breeding in Korea and $57.2 \%$ (14,776 horses) of them are breeding in Jeju island [14].

According to the statistics published in 2010 [10], the horses breeding in Jeju island are subdivided into Jeju horse (6.1\%), Thoroughbred (18.8\%) and Halla horse (75.1\%). Halla horses are defined as a crossbreed between Jeju and Thoroughbred horses and are used for horse racing, horse riding and horse meat production. However, little research has been conducted on Halla horses because of the perception of crossbreed and people's weighted interest toward Jeju horses.

This stduy was conducted to establish parentage and to certify purity of Halla horses using microsatellite markers through the scientific and systemic management and to understand the value of Halla horses as 
genetic resources at national level, and to obtain the basic information on the genetic discrimination from other breeds and conservation of purity and genetic improvement of Halla horses.

\section{Methods}

\section{Animals and DNA extraction}

For the analysis of DNAs using Microsatellite, 3,880 heads of Halla horse breeding in Korea were used. Genomic DNAs were isolated and extracted by the methods described by QuickGene DNA tissue kits (FUJIFILM, Japan) and the concentration and purity of extracted genomic DNAs were measured using ND-1000 UV-Vis Spectrophotometer (NanoDrop Technologies, USA) and used for the analysis.

\section{Information on Microsatellite (MS) Markers}

Genetic diversity of Halla horse was identified using 17 Microsatellite (MS) Markers (AHT4, AHT5, ASB2, ASB17, ASB23, CA425, HMS1, HMS2, HMS3, HMS6, HMS7, HTG4, HTG6, HTG7, HTG10, LEX3, VHL20) recommended by International Society for Animal Genetics (ISAG).

\section{Composition of multiplex-PCR and PCR procedure}

Multiplex-PCR was performed using Equine Genotpyes Panel 1.1 Kit (Thermo SCIENTIFIC) for genotyping of 17 MS Markers. By the manufacturer's instructions, to the reaction mixtures Genomic DNA $(1.0 \mathrm{ng} / \mu \mathrm{l}) 2 \mu \mathrm{l}$, Mater Mix $9 \mu \mathrm{l}$, and Primer Mix $9 \mu \mathrm{l}$ were added, making a total of $20 \mu \mathrm{l}$ and using GeneAmp PCR system 9700 (Applied Biosystems, USA) PCR was performed. PCR was performed in an initial denaturation at $98{ }^{\circ} \mathrm{C}$ for $3 \mathrm{~min}$, followed by 30 cycles of $15 \mathrm{~s}$ at $98^{\circ} \mathrm{C}, 75 \mathrm{~s}$ at $60{ }^{\circ} \mathrm{C}$ and 30 s at $72{ }^{\circ} \mathrm{C}$. The final extension step was at $72{ }^{\circ} \mathrm{C}$ for $5 \mathrm{~min}$ and then cooled to $4{ }^{\circ} \mathrm{C}$.

\section{Genotyping of Microsatellite (MS)}

Using $\mathrm{Hi}-\mathrm{Di}^{\mathrm{Tu}}$ formamide, amplified PCR products were diluted to $50 \sim 100$ times, and the diluted PCR products were diluted using $\mathrm{Hi}-\mathrm{Di}^{\mathrm{mm}}$ formamide and GeneScan ${ }^{\mathrm{ma}}$ 500 $\mathrm{LIZ}^{\mathrm{mix}}$ size standard. After the capillary electrophoresis was performed using Genetic Analyzer 3130xl (Applied Biosystem, USA), the size of each MS marker was determined using GeneMapper version 4.1 (Applied Biosystems, USA). Data on the determined alleles were collected individually and applied to statistical analysis using Microsoft Excel (Microsoft, USA). Also, by the international equine comparison test standards recommended by ISBC (International Stud Book Committee) and ISAG (International Society of Animal Genetics) genotyping was performed and alphabetic allele nomenclature was applied.

\section{Statistical analysis of data}

Frequency, heterozygosity and polymorphism information content

Using Microsatellite Toolkit software [15] and Cervus ver 3.0 program [13], number of alleles, expected and observed heterozygosity $\left(\mathrm{H}_{\exp }\right.$ and $\left.\mathrm{H}_{\mathrm{obs}}\right)$ and Polymorphism information content (PIC) value were calculated.

\section{Frequency of identical individuals}

Using API-CALC ver 1.0 program [1], expected probabilities of appearance frequency of identical individuals in random individuals $(\mathrm{PI})$, random half sibs $\left(\mathrm{PI}_{\text {half-sibs }}\right)$ and random full sibs ( $\left.\mathrm{PI}_{\text {fullsibs }}\right)$ mating population were calculated.

\section{Results and discussion}

Polymorphism of microsatellite markers

For 3,880 heads of Halla horses breeding in Korea, the number of alleles, observed heterozygosity $\left(\mathrm{H}_{\mathrm{obs}}\right)$, expected heterozygosity $\left(\mathrm{H}_{\mathrm{exp}}\right)$ and Polymorphism Information Content (PIC) values of 17 MS markers were calculated (Table 1).

The mean number of alleles for 17 MS markers was 10.41 with a range from 6 (HTG7) to 17(ASB17). Cho [6] reported that there were 7.35 alleles in average with a range from 5(HTG4, HTG7) to 10 (ASB17) in the analysis of genetic characteristics and Genetic Relationship for Jeju horse, Mongolian horse, Thoroughbred and Warmblood when used the same 17 markers used in this study. Similar results were also reported by Cho [7], Cho et al. [5] and Lee et al. [11].

Table 1 No. of Allele, Heterozygosity (observed and expected) and PIC value of microsatellite markers in Halla horses

\begin{tabular}{lllll}
\hline Marker & No of allele & Hobs & Hexp & PIC \\
\hline AHT4 & 11 & 0.843 & 0.835 & 0.814 \\
AHT5 & 10 & 0.810 & 0.808 & 0.781 \\
ASB2 & 13 & 0.857 & 0.843 & 0.824 \\
ASB17 & 17 & 0.790 & 0.770 & 0.746 \\
ASB23 & 13 & 0.802 & 0.814 & 0.789 \\
CA425 & 11 & 0.623 & 0.623 & 0.598 \\
HMS1 & 11 & 0.612 & 0.607 & 0.548 \\
HMS2 & 11 & 0.760 & 0.748 & 0.717 \\
HMS3 & 8 & 0.746 & 0.789 & 0.760 \\
HMS6 & 7 & 0.743 & 0.736 & 0.697 \\
HMS7 & 8 & 0.748 & 0.765 & 0.728 \\
HTG4 & 7 & 0.625 & 0.619 & 0.569 \\
HTG6 & 11 & 0.728 & 0.711 & 0.659 \\
HTG7 & 6 & 0.750 & 0.749 & 0.706 \\
HTG10 & 13 & 0.843 & 0.843 & 0.825 \\
LEX3 & 11 & 0.641 & 0.859 & 0.843 \\
VHL20 & 9 & 0.815 & 0.803 & 0.778 \\
Mean & 10.41 & 0.749 & 0.760 & 0.728 \\
\hline
\end{tabular}


The mean value of $\mathrm{H}_{\text {obs }}$ was 0.749 with a range from 0.612 (HMS1) to 0.857 (ASB2). Also, $\mathrm{H}_{\exp }$ and PIC values were lowest in HMS1 (0.607 and 0.548, respectively), and highest in LEX3 (0.859 and 0.843, respectively). For CA425 the number of alleles was relatively high (11), while $\mathrm{H}_{\mathrm{obs}}, \mathrm{H}_{\exp }$ and PIC values were relatively low (0.623, 0.623 and 0.598 , respectively).

While the number of alleles in HTG7 was lowest (6), $\mathrm{H}_{\text {obs }}, \mathrm{H}_{\exp }$ and PIC values were higher than those of CA425 (0.750, 0.749 and 0.706, respectively), suggesting that alleles in HTG7 were evenly distributed.

Botstein et al. [3] reported that when the expected heterozygosity was above 0.6 and Polymorphism Information Content (PIC) value of MS marker was above 0.5 it is considered as markers with high diversity. Therefore, the 17 MS markers used in this studies are considered as appropriate markers for the analysis of genetic diversity of Halla horses.

\section{The expected probability of identity values}

Using 17 MS markers (AHT4, AHT5, ASB2, ASB17, ASB23, CA425, HMS1, HMS2, HMS3, HMS6, HMS7, HTG4, HTG6, HTG7, HTG10, LEX3, VHL20), the expected probability of identity values in Halla horses were calculated (Table 2). When assumed as random mating population the frequency was $5.90 \times 10^{-20}$ and when assumed as half sib and full-sib mating population the frequencies were $4.08 \times 10^{-15}$ and $3.56 \times 10^{-8}$, respectively. From these results, 17 MS markers used in this study can be applicable for Individual Identification and Parentage Verification of Halla horses.

\section{Allele frequency of microsatellite markers}

\section{AHT4}

In Halla horses, a total of 11 alleles in AHT4 marker were detected and their frequencies are shown in Fig. 1. Frequencies of 3 alleles $(\mathrm{O}, \mathrm{H}$ and $\mathrm{P})$ were relatively high
Table 2 The expected probability values among genotypes of random individual (PI) for discrimination horse lines using markers

\begin{tabular}{llll}
\hline No. of Marker & Random & Half-sib & Sib \\
\hline 1 & $3.20 \times 10^{-2}$ & $8.09 \times 10^{-2}$ & $3.09 \times 10^{-1}$ \\
2 & $1.22 \times 10^{-3}$ & $7.33 \times 10^{-2}$ & $9.77 \times 10^{-2}$ \\
3 & $4.76 \times 10^{-5}$ & $6.70 \times 10^{-2}$ & $3.11 \times 10^{-2}$ \\
4 & $2.04 \times 10^{-6}$ & $6.52 \times 10^{-5}$ & $1.00 \times 10^{-2}$ \\
5 & $1.08 \times 10^{-7}$ & $7.29 \times 10^{-6}$ & $3.37 \times 10^{-3}$ \\
6 & $6.10 \times 10^{-9}$ & $8.50 \times 10^{-7}$ & $1.14 \times 10^{-3}$ \\
7 & $3.49 \times 10^{-10}$ & $1.01 \times 10^{-7}$ & $3.89 \times 10^{-4}$ \\
8 & $2.30 \times 10^{-11}$ & $1.31 \times 10^{-8}$ & $1.36 \times 10^{-4}$ \\
9 & $1.58 \times 10^{-12}$ & $1.83 \times 10^{-9}$ & $4.87 \times 10^{-5}$ \\
10 & $1.30 \times 10^{-13}$ & $2.73 \times 10^{-10}$ & $1.78 \times 10^{-5}$ \\
11 & $1.23 \times 10^{-14}$ & $4.44 \times 10^{-11}$ & $6.66 \times 10^{-6}$ \\
12 & $1.03 \times 10^{-15}$ & $7.00 \times 10^{-12}$ & $2.49 \times 10^{-6}$ \\
13 & $9.90 \times 10^{-17}$ & $1.18 \times 10^{-12}$ & $9.47 \times 10^{-7}$ \\
14 & $1.20 \times 10^{-17}$ & $2.29 \times 10^{-13}$ & $3.78 \times 10^{-7}$ \\
15 & $1.79 \times 10^{-18}$ & $5.66 \times 10^{-14}$ & $1.69 \times 10^{-7}$ \\
16 & $3.10 \times 10^{-19}$ & $1.48 \times 10^{-14}$ & $7.66 \times 10^{-8}$ \\
17 & $5.90 \times 10^{-20}$ & $4.08 \times 10^{-15}$ & $3.56 \times 10^{-8}$ \\
\hline & & &
\end{tabular}

(25.52, 18.12 and 16.13 , respectively), while those of 3 alleles $(\mathrm{G}, \mathrm{Q}$, and $\mathrm{M})$ were low $(0.01,0.03,0.08$, respectively). It was reported that repeat structure of AHT4 was $(\mathrm{AC})_{\mathrm{n}} \mathrm{AT}(\mathrm{AC})_{\mathrm{n}}$ (Genbank : Y07733) and the allele with repeat of $(\mathrm{AC})_{18} \mathrm{AT}(\mathrm{AC}){ }_{9}$ was allele $\mathrm{K}$ and the frequency was similar to that of this experiment processed by alphabetic nomenclature $[7,11,17]$. Allele $\mathrm{G}$ was not detected when alleles of AHT4 were investigated for the 9,094 horses of 35 breeds including Thoroughbred [17]. However, Cho [7] reported that although low in allele frequency $(0.0002)$, it was detected in the parentage test of Thoroughbred horses breeding in Korea. This result suggests that if the genetic improvement and breeding

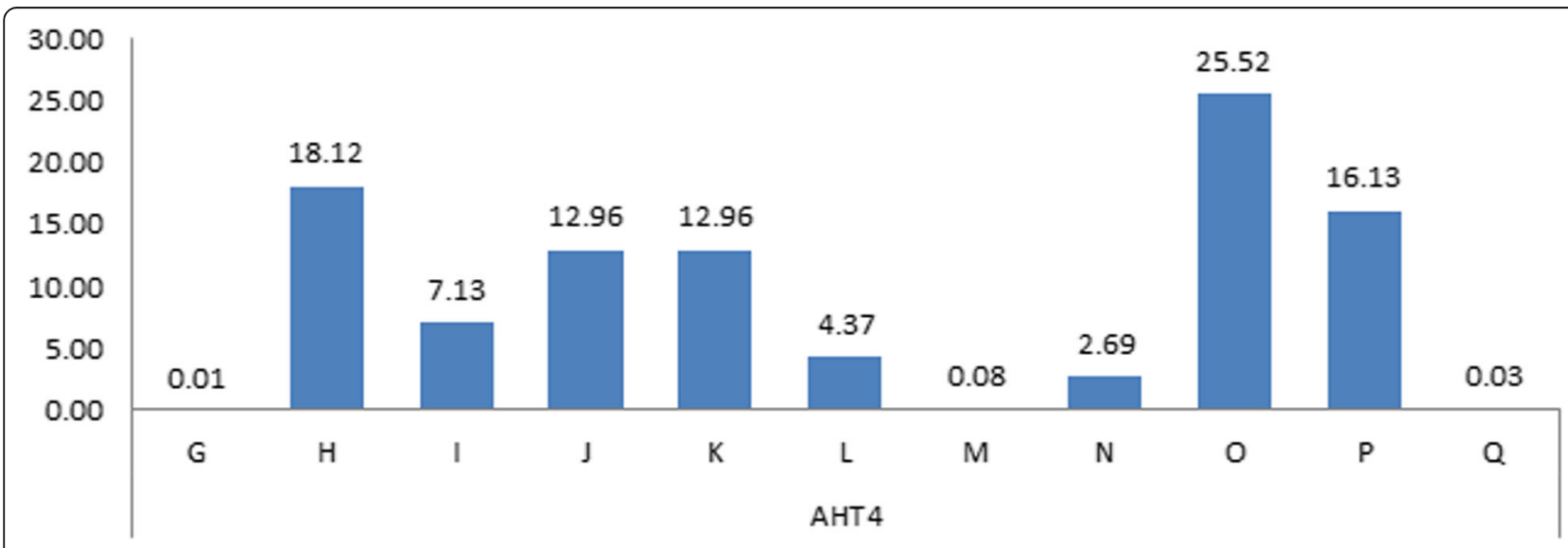

Fig. 1 Alleles and allele's frequencies for the Microsatllite AHT4 in the studied breeds 


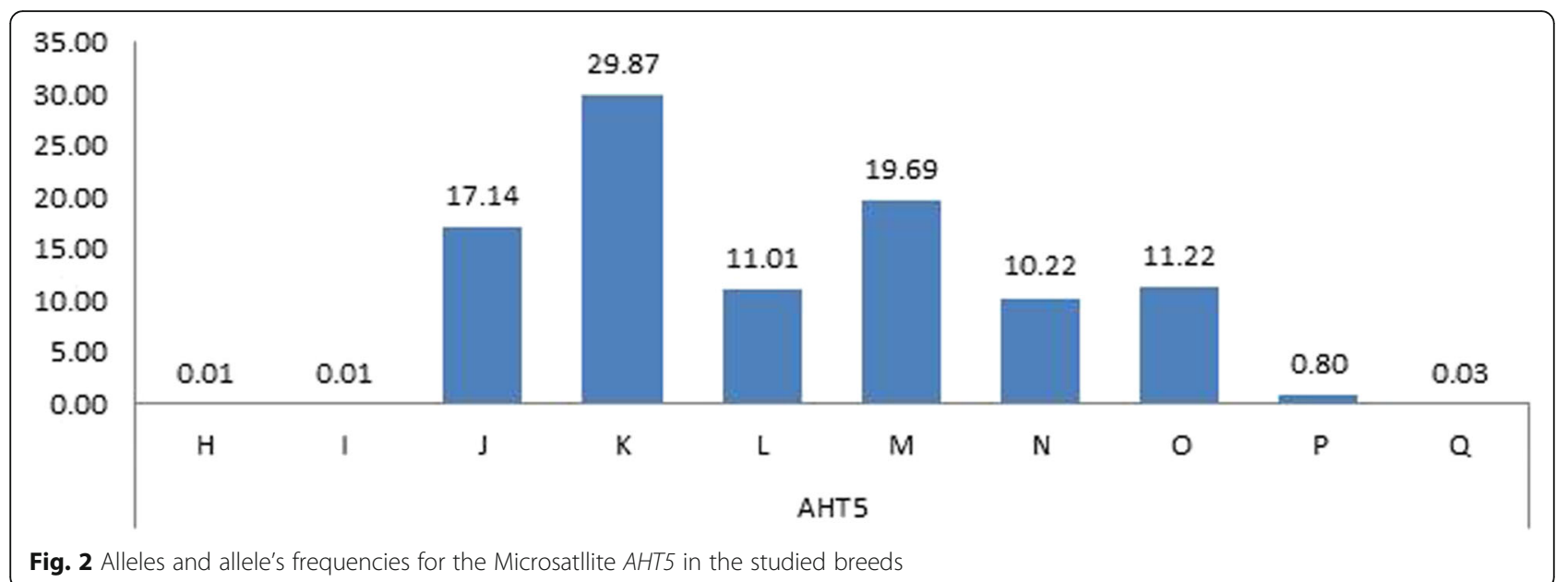

goals are established through the research on allele $G$ in Thoroughbred and Halla horses breeding in Korea, it will be useful for the discrimination of domestic and foreign breeds of horse.

\section{AHT5}

AHT5 has simple dinucleotide repeats of $(\mathrm{GT})_{\mathrm{n}}$ (Genbank : Y07732)) and in Halla horses a total of 10 alleles were detected in AHT5 marker. Frequency of allele is shown in Fig. 2. The frequency of allele $\mathrm{K}$ was high (29.87), while frequencies of allele $\mathrm{H}$ and I were low (0.01). Similar results were reported in Korea, but in the studies conducted in foreign countries the frequencies of allele $\mathrm{J}$ and $\mathrm{N}$ were high $(0.24$ and 0.22 , respectively) [17]. Also, for allele Q, it was low (0.0002) as in allele G of AHT4 in the parentage test of Thoroughbred breeding in Korea. Therefore, since allele Q of AHT5 was detected in Thoroughbred and Halla horses in Korea, further research on allele $Q$ is needed to obtain the useful information for the discrimination of domestic and foreign horse breeds as allele G of AHT4.

\section{HMS2}

HMS2 has dinucleotide repeats of $\left.(\mathrm{CA})_{n}(\mathrm{TC})_{2}\right)$ (Genbank : X74631)) and a total of 11 alleles were detected in HMS2 marker of Halla horses and their frequencies are shown in Fig. 3. The frequencies were high in the order of allele L, K and I $(42.18,20.08$ and 14.38, respectively), while those of allele $\mathrm{N}$ and $\mathrm{G}$ were lowest (0.01). Van de Goor et al. [17] reported that in 35 horse breeds the frequencies in HMS2 were high in allele of $\mathrm{K}$ and $\mathrm{H}$ and frequencies of allele $\mathrm{Q}, \mathrm{S}$ and $\mathrm{U}$ which were not detected in Halla horses were low. Also, although low (0.01), allele $\mathrm{G}$ was detected only in Halla horses. This specific allele can be used for the basic information for breed discrimination. The other markers were written into Additional file 1.

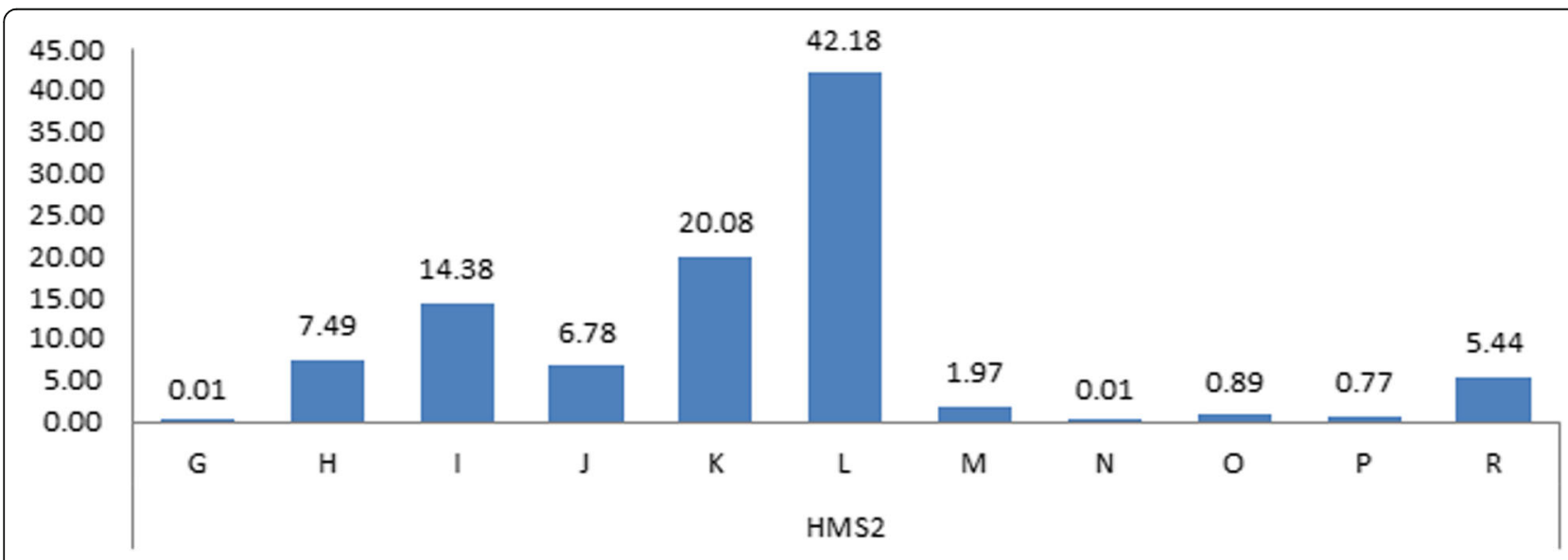

Fig. 3 Alleles and allele's frequencies for the Microsatllite HMS2 in the studied breeds 


\section{Conclusion}

Although several studies $[2,8,9,12]$ reported population studies on the genetic pedigree structure of several horse breeds, only limited information is available about data needed in casework such as the power of identity and breed assignment $[4,16]$. In this study, allele $M$ and $Q$ of ASB23 marker, G of HMS2 marker, H and L of HTG6 marker, L of HTG7 marker, E of LEX3 marker confirmed as the specific alleles unique to Halla horses. This result is considered that utilize for the basic information on genetic resource and genetic relationship analysis of Halla horses. Also, it is thought to used as scientific evidence that prove pedigree establishment, genetic differentiation and inherency of halla horses. Finally, It is considered to be a useful data in the improved ability to breed Halla horses.

\section{Additional file}

Additional file 1: Allele frequency of Microsatellite Markers. (DOCX $128 \mathrm{~kb}$ )

\section{Acknowledgement}

This research was supported by the Genomic Informatics Center, Hankyong National University and korea Hallahorse Breeder's Association.

\section{Funding}

Funding came from korea Hallahorse Breeder's Association.

Availability of data and materials

Not applicable.

\section{Authors' contributions}

$\mathrm{JH}$ carried out the molecular genetic studies and drafted the manuscript. KD and HK collected samples. HS conceived of the study, and participated in its design and coordination and helped to draft the manuscript. All authors read and approved the final manuscript.

\section{Competing interests}

The authors declare that they have no competing interests.

\section{Consent for publication}

Not applicable.

\section{Ethics approval}

The study was approved by the HanKyung National University Animal Ethics Committee (No. 2015-4).

\section{Author details}

${ }^{1}$ Genomic Informatics Center, Hankyong National University, Anseong 17579, Korea. ${ }^{2}$ Department of Genomic Informatics, Graduate School of Future Convergence Technology, Hankyong National University, Anseong 456-749, Korea. ${ }^{3}$ ChonBuk National University, Jeonju 54896, Korea.

Received: 17 April 2016 Accepted: 17 October 2016

Published online: 17 November 2016

\section{References}

1. Ayres KL, Overall ADJ. API-CALC 1.0: computer program for calculating the average probability of identity allowing for substructure, inbreeding and the presence of close relatives. Mol Ecol Notes. 2004;4:315-8.

2. Azor PJ, Valera M, Go'mez MD, et al. Genetic characterization of the Spanish Trotter horse breed using microsatellite markers. Genet Mol Biol. 2007:30:37-42
3. Botstein D, White RL, Skolnick M, Davis RW. Construction of a genetic linkage map in man using restriction fragment length polymorphisms. Am J Hum Genet. 1980;32:314-31.

4. Cañon J, Checa ML, Carleos C, et al. The genetic structure of Spanish Celtic horse breeds inferred from microsatellite data. Anim Genet. 2000;31:39-48.

5. Cho BW, Jong JH, Kim SW, Kim HS, Lee HK, Cho GJ, Song GD. Establishment of genetic characteristics and individual identification system using microsatellite loci in Jeju native horse. J Life Sci. 2007;17:1441-6.

6. Cho GJ. Genetic relationship and characteristics using microsatellite DNA loci in horse breeds. J Life Sci. 2007;17:699-705.

7. Cho GJ. Parentage testing for thoroughbred horse by microsatellite DNA typing. J Anim Sci Technol (Kor). 2004;42:129-36.

8. Choi SK, Cho CY, Yeon SH, et al. Genetic characterization and polymorphisms for parentage testing of the Jeju horse using 20 microsatellite loci. J Vet Med Sci. 2008;70:1111-5.

9. Giacomoni EH, Ferna'ndez-Stolz GP, Freita TR. Genetic diversity in the Pantaneiro horse breed assessed using microsatellite DNA markers. Genet Mol Res. 2008;18:261-70.

10. Jeju Special Self-Governing Province. A study on the appropriate utilization of Jeju crossbred horse; 2013.

11. Lee SY, Kang SW, Cho IS, Hu MB, Kim SJ, Han MS. A Case of Parentage Testing for Thoroughbred Horse by Microsatellite DNA Typing. Korean J Forensic Sci. 2006;7:70-5.

12. Marletta D, Tupac-Yupanqui I, Bordonaro S, et al. Analysis of genetic diversity and the determination of relationships among western Mediterranean horse breeds using microsatellite markers. J Anim Breed Genet. 2006;123:315-25.

13. Marshall TC, Slate J, Kruuk LEB, Pemberton JM. Statistical confidence for likelihood-based paternity inference in natural populations. Mol Ecol. 1998;7:639-55.

14. Ministry of Agriculture, Food and Rural Affairs. 2014 Actual condition survey of horse industry; 2015.

15. Park SDE. The excel microsatellite toolkit (version 3.1). 2001.

16. Thirstrup JP, Pertoldi C, Loeschcke V. Genetic analysis, breed assignment and conservation priorities of three native Danish horse breeds. Anim Genet. 2008:39:496-505

17. Van de Goor LHP, Panneman H, van Haeringen WA. A proposal for standardization in forensic equine DNA typing: allele nomenclature for 17 equine-specific STR loci. Anim Genet. 2009;41:122-7.

Submit your next manuscript to BioMed Central and we will help you at every step:

- We accept pre-submission inquiries

- Our selector tool helps you to find the most relevant journal

- We provide round the clock customer support

- Convenient online submission

- Thorough peer review

- Inclusion in PubMed and all major indexing services

- Maximum visibility for your research

Submit your manuscript at www.biomedcentral.com/submit 